\title{
Nurses views of interprofessional education and collaboration: A comparative study of recent graduates from three universities
}

\author{
Margareta Wilhelmsson, Annemie Svensson, Toomas Timpka and Tomas Faresjö
}

\section{Linköping University Post Print}

\section{Tweet}

N.B.: When citing this work, cite the original article.

Original Publication:

Margareta Wilhelmsson, Annemie Svensson, Toomas Timpka and Tomas Faresjö, Nurses views of interprofessional education and collaboration: A comparative study of recent graduates from three universities, 2013, Journal of Interprofessional Care, (27), 2, 155-160. http://dx.doi.org/10.3109/13561820.2012.711787

Copyright: Informa Healthcare http://informahealthcare.com/

Postprint available at: Linköping University Electronic Press http://urn.kb.se/resolve?urn=urn:nbn:se:liu:diva-90670 
NURSES' VIEWS OF INTERPROFESSIONAL EDUCATION AND

COLLABORATION: A COMPARATIVE STUDY OF RECENT GRADUATES

FROM THREE UNIVERSITIES IN SWEDEN

Wilhelmsson M., Svensson A., Timpka T. and Faresjö T.

Department of Medicine and Health/Community Medicine

Faculty of Health Sciences, Linköping University, Sweden 


\section{Abstract}

Today interprofessional education is spread throughout the world. In Sweden only one of the existing nursing programmes has an IPE curriculum on several levels during the training.

The aim of this study was to examine how nurses who recently graduated from universities with IPE or non-IPE curricula perceive the importance of different educational goals and whether they found themselves prepared for their profession, and especially for collaboration with other professions.

Three universities with different commitments to interprofessional education were studied.

We used a survey with eight different targets: communication skills, co-operation with other professions, problem solving capability, self-directed learning skills, whether their education has prepared them to work professionally, to perform research, to take care of acutely ill patients, to work preventively and working as a nurse. The participants were asked if their undergraduate education had prepared them for these targets and if they perceived that the targets were important goals for their education.

A main result in this study was that nurses who had recently graduated from the IPEuniversity perceived to a greater extent that their undergraduate training had prepared them to work together with other professions in comparison with nursing students from non-IPE universities.

Key words: Interprofessional education, evaluation, curricula. 


\section{Introduction}

To promote effective teamwork in health care, the World Health Organization (WHO), following the Alma-Ata declaration (WHO 1978), encouraged the development of interprofessional education (IPE) activities around the world (WHO, 1988). The basic idea was that it is favourable for undergraduate students and the development of their own professional identity to experience other professions in the health and social sectors during their undergraduate studies. Inherent in this scheme was that various professions would work together in practical ways. The universal winner in this new way of thinking about education and health care practice was to be the patient (Wilhelmsson, Pelling, Ludvigsson, Hammar, Dahlgren and Faresjö, 2009). Today more than 30 years after the first recommendations, WHO has again focused on "learning together to work together" (WHO 2006, 2010). As a result, IPE is advancing in for example United Kingdom, Canada, Australia, America and the Nordic Countries (Anderson \& Lennox, 2009; Grant, Brainbridge and Gilbert, 2010; Lee, Dunstone, Nisbe, Matthees and Pockett, 2009; Report of an expert panel, 2011; Areskog, 2009). There are many universities running IPE curricula on different levels in their undergraduate programmes in these countries. However, only one of the nursing programmes in Sweden has such IPE curricula. Nursing education in Sweden is strictly regulated by the Government (Higher Education Act, 1992:1434). The overall objective for nursing education is "to go beyond knowledge and skills, giving the students the capacity for independent and critical evaluation, the ability to solve problems independently and to follow the development of knowledge in the field." The lower level targets include acquisition of "skills in planning, management and co-ordination of health care work", and developing "a professional role in preparation for teamwork and collaboration between all staff groups" (Higher Education Act, 1992:1434). 
Interprofessional communication and collaboration are promoted by policymakers as fundamental building blocks for improving patient safety and for meeting the requirements of an increasingly complex health care system in a multi-ethnic society. However, a Canadian report concluded that IPE intervention with communication and collaboration at undergraduate level did not produce the anticipated changes in communication and collaboration between health professionals. Professional resistance as well as the fast-paced, interruptive environment reduced opportunities or incentives to relationships (Rice, Zwarenstein, Gotlibe, Kenazchuk, Russel and Reeves, 2010).

Whether interprofessional education can survive the transition into clinical practice is therefore important. Students interviewed about their clinical training placements perceived that the quality of interprofessional interaction mainly depended on interpersonal communication (Pollard \& Miers, 2008) and some staff in placement settings experienced problems when working with colleagues from other professions (Pollard, 2008). However, professionals who were educated in interprofessional curricula were more confident concerning professional interaction, and positive correlations were shown between students' perceptions of their relevant skills and their interprofessional relationships (Pollard \& Miers, 2008). But during qualification and practice the interprofessional cohort grew more critical of interprofessional education (Pollard \& Miers, 2008). Understanding more about personal learning needs can contribute to better preparation for interprofessional interaction and teamwork (Morison, Johnston \& Stevenson, 2010). Indicators for positive teamwork have been found to be, for example, personal qualities, staff commitment, communication within the team and the opportunity to develop creative working methods within the team (Molyneux, 2001). A review of the literature on integrated teamwork identified four important themes: drivers, barriers and benefits of integrated work, staff development and meeting the needs of service (Maslin-Prothero \& Bennion, 2010). 
Studies have shown that students, who have been educated with IPE curricula, have positive attitudes both towards their own and other professional groups (Hind, Norman, Cooper, Gill, Hilton, Judd and Jones, 2003). Also, empirical work has indicated that IPE can fail to alter poor stereotypical perceptions of each other (Mandy, Milton and Mandy, 2004). While in another study, there were no significant differences between medical students who had an IPE curriculum and those who had not with regard to their attitudes to collaboration with nurses (Hansson, Foldevi, and Mattsson, 2010). By splitting up the cohort in gender the female medical students were significant more positive about collaboration with nursing students than male medical students (Hansson et al., 2010). By using the RIPELS-instrument (Parsell \& Bligh, 1998) in Sweden the most important item to have "readiness for interprofessional learning" was to be a woman (Wilhelmsson, Ponzer, Dahlgren, Timpka and Faresjö, 2011). Evaluations of all newly graduated Swedish medical doctors have showed, that those who had been exposed to IPE reported significantly more confidence than the others that their undergraduate studies had given them interprofessional skills and ability to co-operate with other professions (Faresjö, Wilhelmsson, Pelling, Dahlgren, and Hammar, 2007). The same result as reported above has been constant for the last ten years (The Swedish Medical Association).

\section{Methods}

This study aimed to examine how nurses who recently graduated from universities with or without IPE curricula perceive the importance of different educational goals and whether they found themselves to have been prepared for their profession, and especially for collaboration with other professions. 


\section{Study context}

Three universities with different commitments to interprofessional education were studied. One of the universities was labelled "the IPE University." For over 20 years this university has had an extensive interprofessional commitment offering an IPE curriculum for all their students in the health sciences (Areskog, 1992, 2009; Wilhelmsson et al., 2009). This university also features problem-based learning (PBL) as the pedagogical method (Silén, 1996; Silén \& Uhlin, 2008; Dahlgren, 2009). All health care students at this university are exposed to IPE activities for at least 12 weeks during their undergraduate education, from integrated courses early on and in the middle of their education to a final two-week interprofessional practice on a student training ward (Fallsberg \& Wijma, 1999; Fallsberg \& Hammar, 2000; Wahlström, Sandén \& Hammar, 1996; Wahlström \& Sandén, 1998).

The two other studied universities were labelled "non-IPE Universities" since they have a more traditional curriculum design. Their curricula highlight other issues like communication, family care, IT and international perspectives and not IPE.

\section{Data collection}

A questionnaire focusing on how undergraduate studies had prepared nurse-students for a set of educational targets was sent by mail to all nurse-students one year after graduation from nursing programmes at universities in southeast of Sweden. The questionnaire was mailed together with an information letter to the respondents in 2008. 554 nurses, who graduated spring or autumn 2007, were invited to participate in the study out of which 303 nurses filled 
in the questionnaire after one reminder, giving an overall response rate of 55\%. The sex and age distribution was comparable between the three universities, with no significant differences in this respect.

The questionnaire used in this study is based on a previously presented one (Hård af Segerstad, 1998). It has been used for many years by the Swedish Medical Association as a tool to evaluate medical undergraduate education at the medical faculties in Sweden (Faresjö el al., 2007). The main question raised was if the students perceived that their undergraduate education had prepared them for certain fundamental features and goals. There were eight different goals: communication skills, cooperation with other professions, problem-solving capability, self-directed learning skills, whether their education has prepared them to work professionally, to perform research, to take care of acutely ill patients, and to work preventively. All questions were answered on a six-point Likert scale, from 1 "I completely disagree" to 6 "I completely agree."

\section{Analysis}

The data were split in two groups "IPE- University" and "Non-IPE University", stored in a database and statistically analysed using the Statistical Package for the Social Sciences (SPSS) 18.0 software (Chicago, IL, USA). ANOVA was used for univariate tests. A p-value of $<0.05$ was considered statistically significant.

\section{Ethics}

The Research Ethics Committee at Linköping University, Sweden, approved the study (Dnr. 2010/26-31). 


\section{Results}

There were only minor differences between the newly graduated nurses from the IPE University and the non-IPE Universities regarding how they perceived the importance of different educational goals (see Table 1). However, the educational goal to develop good leadership in health care was significantly $(\mathrm{p}=0.003)$ more cherished among the nurses from the IPE University.

Table 1. Perceptions among newly graduated nurses concerning how important different educational goals appear to be for their education.

\begin{tabular}{|c|c|c|c|c|c|}
\hline \multirow{2}{*}{$\begin{array}{l}\text { How important for your } \\
\text { education as a nurse do you } \\
\text { recognize these educational } \\
\text { goals to be? }\end{array}$} & \multicolumn{2}{|c|}{$\begin{array}{l}\text { IPE University } \\
\qquad \mathbf{N}=179\end{array}$} & \multicolumn{2}{|c|}{$\begin{array}{l}\text { Non-IPE Universities } \\
\qquad \mathbf{N}=\mathbf{1 1 8}\end{array}$} & \\
\hline & mean & s.d & mean & s.d & p-value \\
\hline Prepared to work as a nurse & 5.68 & 0.73 & 5.61 & 0.81 & 0.395 \\
\hline $\begin{array}{l}\text { Co-operate with other } \\
\text { professions }\end{array}$ & 5.39 & 0.90 & 5.19 & 1.03 & 0.092 \\
\hline $\begin{array}{l}\text { Good leadership in health } \\
\text { care }\end{array}$ & 5.17 & 0.97 & 4.81 & 1.01 & 0.003 \\
\hline Communication with patients & 5.63 & 0.75 & 5.58 & 0.90 & 0.613 \\
\hline Lifelong learning & 5.19 & 1.00 & 5.05 & 0.99 & 0.263 \\
\hline Interest in research & 3.13 & 1.52 & 3.20 & 1.42 & 0.714 \\
\hline Managing acutely sick patient & 5.61 & 0.84 & 5.55 & 0.94 & 0.555 \\
\hline Preventive work & 5.18 & 1.03 & 5.36 & 1.05 & 0.152 \\
\hline
\end{tabular}


Nurses' perceptions of how their undergraduate education had prepared and developed them for eight different educational targets and skills are shown in Table 2. All the respondents in the survey stated that the most important goal of their nursing education was to be prepared to "work as a nurse," followed by "communication with patients", "managing sick patients" and "co-operating with other professions."

Table 2. Perceptions among nurses concerning how their undergraduate education has prepared and developed different types of skills, comparison between a university with an IPE curriculum vs universities without an IPE curriculum.

\begin{tabular}{|l|c|c|c|c|c|}
\hline & \multicolumn{2}{|l|}{ s.d } & \multicolumn{2}{l}{ Non-IPE Universities } & \\
$\begin{array}{l}\text { Has your undergraduate } \\
\text { education prepared you and } \\
\text { developed your skills: }\end{array}$ & \multicolumn{2}{|c|}{ IPE University } & \multicolumn{2}{c|}{$\mathbf{N}=118$} & \\
\hline & mean & mean & s.d & p-value \\
\hline To work as a nurse? & 4.20 & 1.24 & 3.77 & 1.16 & 0.003 \\
\hline $\begin{array}{l}\text { To co-operate with other } \\
\text { professions? }\end{array}$ & 4.37 & 1.26 & 3.53 & 1.20 & $<0.0001$ \\
\hline $\begin{array}{l}\text { For good leadership in health } \\
\text { care? }\end{array}$ & 3.44 & 1.26 & 3.25 & 1.20 & 0.216 \\
\hline $\begin{array}{l}\text { For communicating with } \\
\text { patients? }\end{array}$ & 4.44 & 1.20 & 4.03 & 1.331 & 0.006 \\
\hline For lifelong learning? & 4.47 & 1.35 & 4.18 & 1.52 & 0.091 \\
\hline For interest in research? & 2.71 & 1.53 & 2.64 & 1.50 & 0.719 \\
\hline $\begin{array}{l}\text { To manage an acutely sick } \\
\text { patient? }\end{array}$ & 2.75 & 1.39 & 3.06 & 1.38 & 0.059 \\
\hline To work preventively? & 3.58 & 1.23 & 3.68 & 1.28 & 0.504 \\
\hline
\end{tabular}

Nurses who had been exposed to interprofessional curricula during their undergraduate education reported to a significantly greater extent $(\mathrm{p}=0.003)$ that they were prepared to 
work as a nurse (see figure 1). Further, they also reported to a significantly greater extent $(\mathrm{p}<$ 0.0001) that their undergraduate education had prepared them to work with other health care professions as shown in Figure 2, and also to communicate with patients $(\mathrm{p}=0.006)$, shown in Figure 3.

Figure 1. Perceptions among nurses of how their undergraduate education has prepared and developed their skills to work as a nurse. (Percentage on a 6-degree Likert scale from "Completely Disagree" to "Completely Agree".)

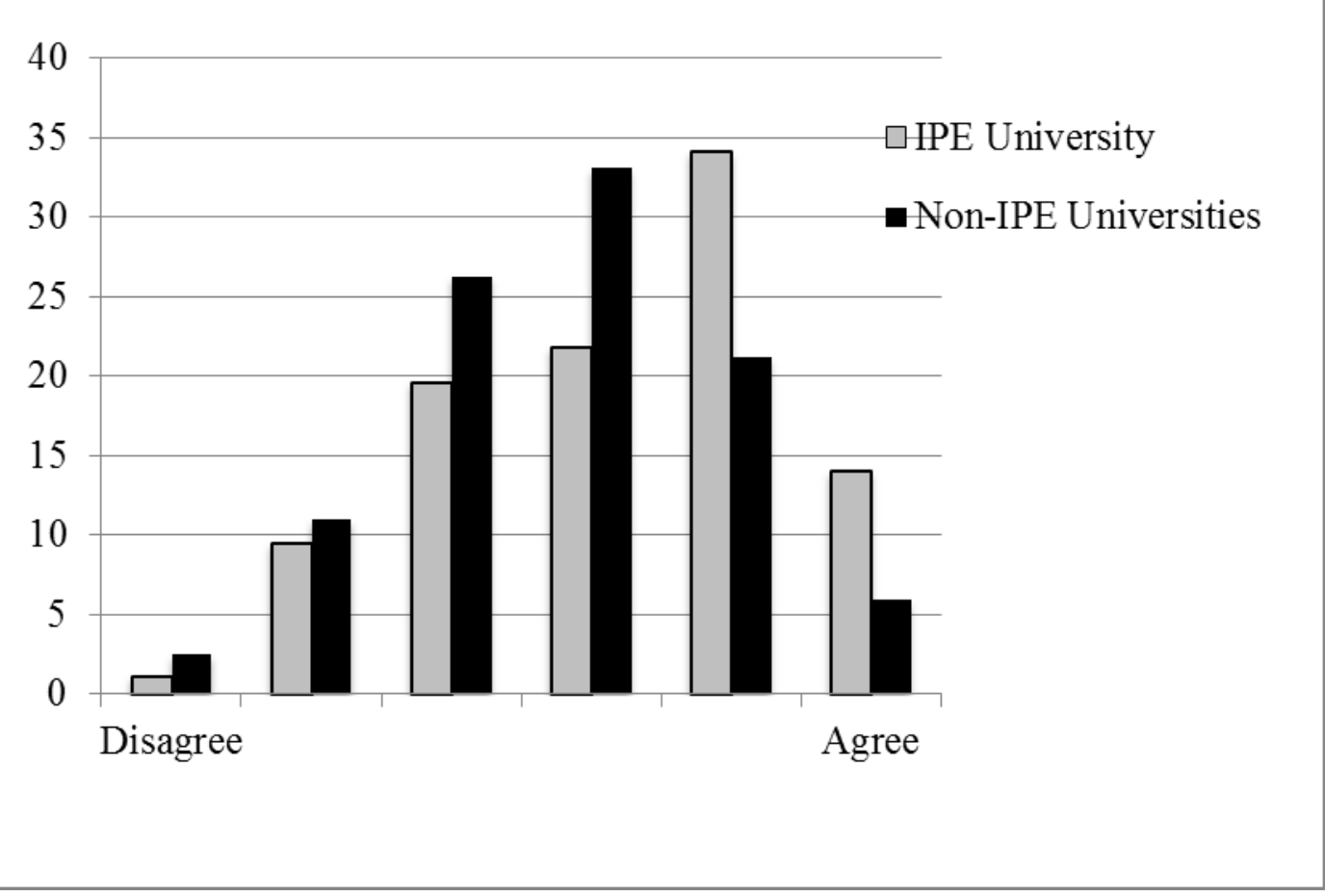


Figure 2. Perceptions among nurses of how their undergraduate education has prepared and developed their co-operation skills with other health care professions. (Percentage on a 6-degree Likert scale from "Completely Disagree" to "Completely Agree".)

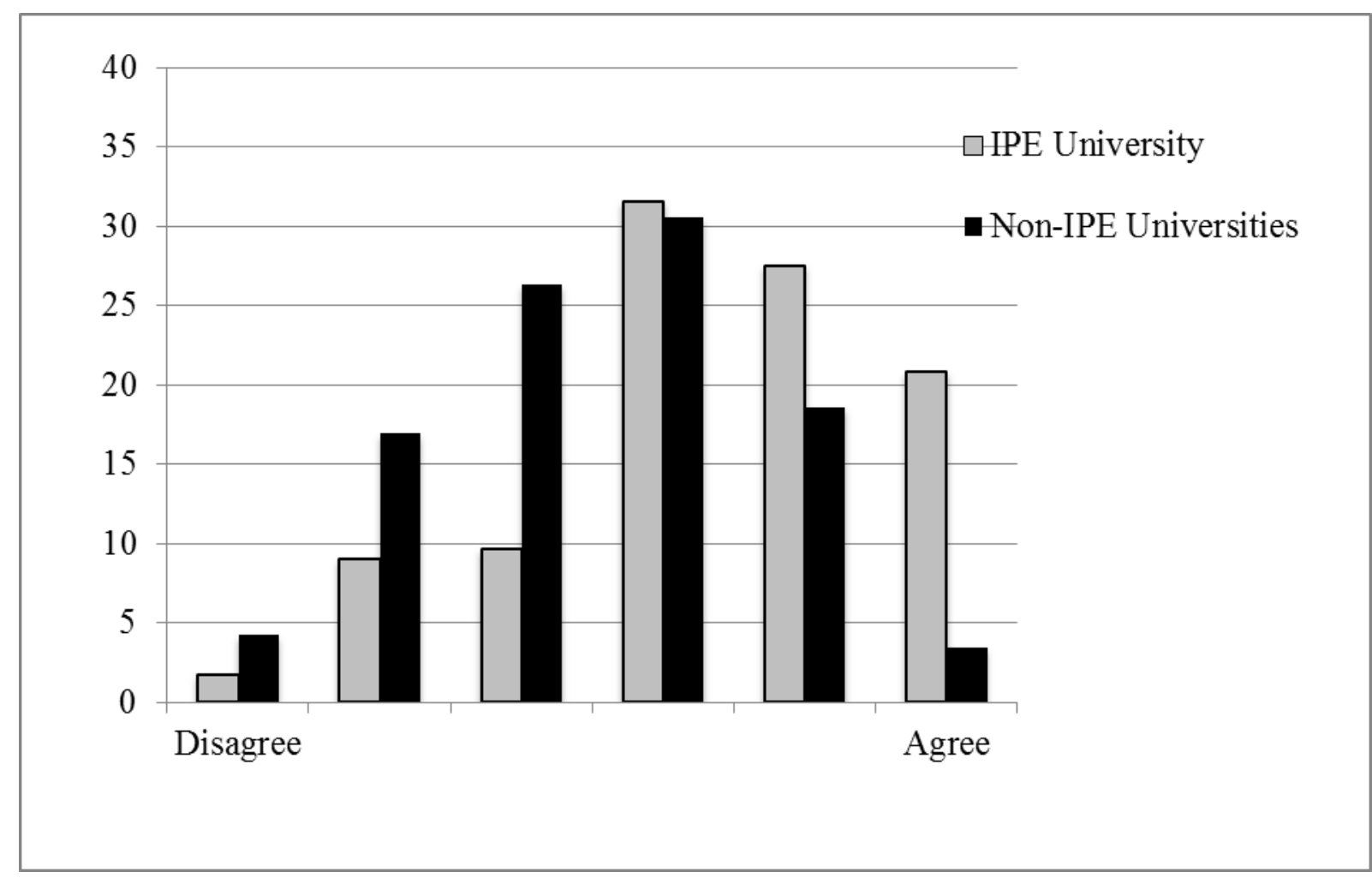

Figure 3. Perceptions among nurses of how their undergraduate education has prepared and developed their communication skills with patients. (Percentage on a 6-degree Likert scale from "Completely Disagree" to "Completely Agree".)

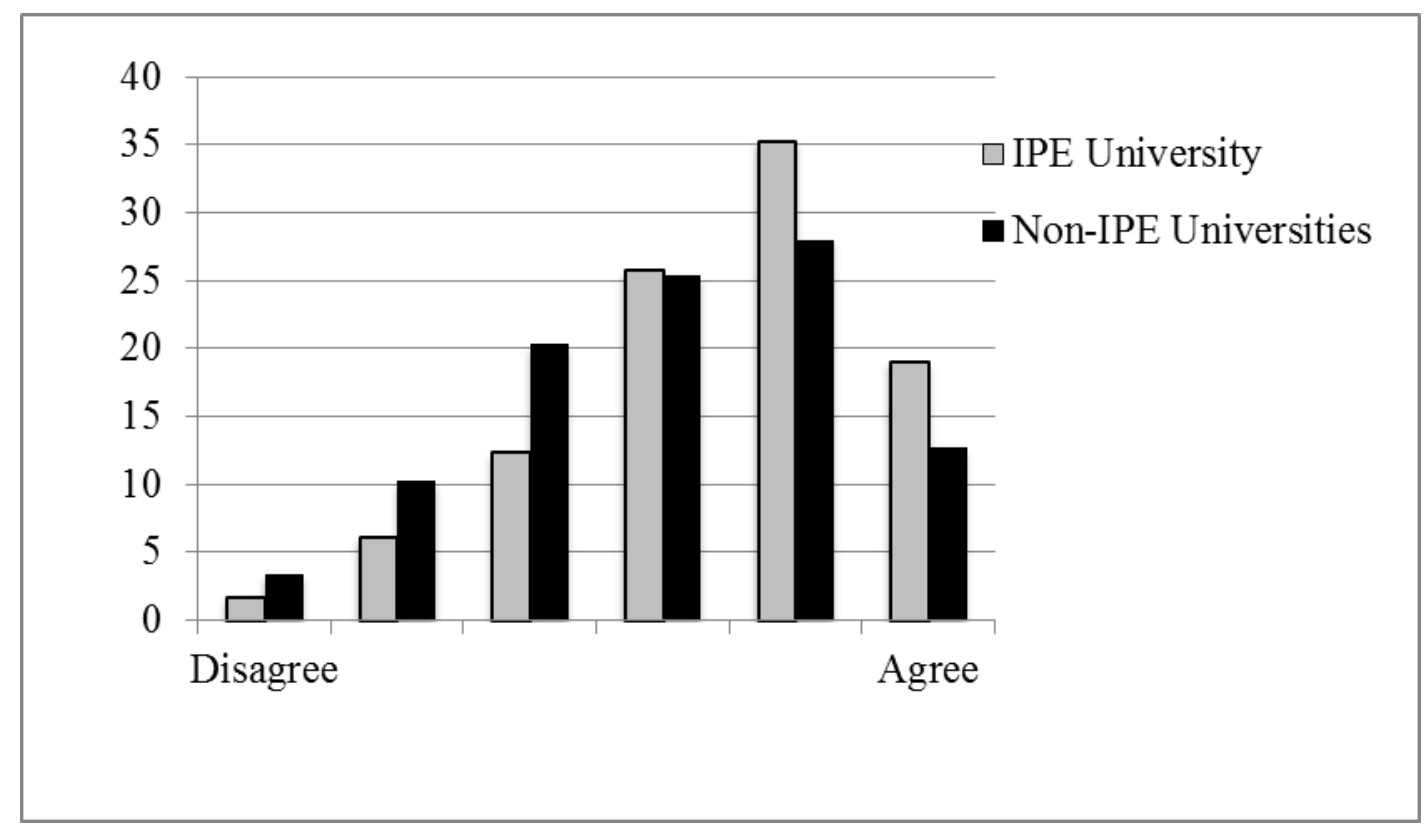


There was a tendency $(\mathrm{p}=0.091)$ towards the view that lifelong learning skills were more frequently perceived to have been gained by nurses who had graduated from the IPE University, while confidence in how to manage acutely sick patients tended to be higher ( $\mathrm{p}=$ 0.059) among the nurses from the non-IPE University. There were no differences concerning interest in doing research or working preventively between the two types of universities.

\section{Discussion}

The main findings in this study was that nurses who had recently graduated from the IPE University perceived to a greater extent that their undergraduate training had prepared them to work together with other professions in comparison with nursing students from non-IPE universities. These results are quite similar to previous findings based on national evaluations of all medical programmes in Sweden (Faresjö et al., 2007). However, in this present study there was not any statistical significant difference between nurses from the IPE-university and non-IPE university concerning their perception of how their undergraduate education had prepared and developed them how to manage acutely sick patients. The same trend was found in the previous study comparing medical students from the IPE-university to medical students from other universities in Sweden (Faresjö et al., 2007). Another comparison between these two studies shows that medical students in general scored higher that they were prepared to manage acute sick patients than nursing students. This indicates that medical undergraduate education put more emphasis on these skills than nursing education. Another study of nurses in Sweden concluded that newly graduated nurses in general did not have the skills to act in acute medical situations (Ohlsson, 2009). There might be a difference between medical and 
nursing programs as to how well the undergraduate education actually prepares the students for acute patient's situations.

The investment in interprofessional education during undergraduate education at the IPE University seemed to pay off, at least considering the students' perceptions regarding whether they were prepared to collaborate with other professions. This seems to include both medical and nursing students. A perception can be merely an attitude and not reflect real-world action. However, having a mental readiness for interprofessional collaboration with other professions is an important prerequisite and a good starting point for interprofessional action.

Only one nursing programme in Sweden has a thorough IPE curriculum even though nursingstudents, as reported in this study, think that interprofessional collaboration is an important goal in undergraduate education. One could raise the question of why so few universities in Sweden have an IPE curriculum when one of the targets for undergraduate education for nurses is "to developed a professional role in preparation for teamwork and collaboration among all staff groups" (Higher Education Act 1992:1434) and also in view of the Alma-Ata declaration (WHO 1978) and "Learning together to work together" (WHO, 1988, 2006, 2010). This issue must be discussed in relation to the question of how autonomous one is as an educational designer and how education is controlled to attain the targets recommended by the government. 
In this study nurses from the IPE University reported to a significantly greater extent that leadership in health care was an important educational goal. An interesting finding is that nurses who have been trained in an IPE curriculum realized that leadership in health care is important. This finding might be interpreted to mean that nursing students who have met other professionals during their education and worked together with them in small groups have found out that there is no obvious leader. Nurses often expect the doctors to be the leaders, which is also the general picture in a traditional hierarchical health care system. On the other hand, practical everyday experiences during their education make many students realize that the personality of the human being is sometimes even more important in teamwork than one's formal education.

The importance of the questions of "how your education has prepared you to work as a nurse" and "to communicate with patients" was also reported to be significantly higher among nurses from the IPE University. In other reports it was found that students who have been exposed to IPE curricula during their education were more confident upon qualification about their communicative skills, their interprofessional relationships and their professional interactions (Pollard, 2008). Students who encounter other ways of expressing and solving problems and different perspectives of phenomena might be widening their communicative skills. Interaction during education between students from different programmes is also important for the understanding of other professions working models, culture and language and, not least, for mirroring their own profession, being reflective and aware of both the core and the limits of the own profession (Clark, 2009; Wackerhausen, 2009; Wilhelmsson, 2012). 
Limitations of the study are that we have used an evaluation instrument and focused on only some of the eight questions (cooperation, communication and work as nurse), but we chose this approach because we wanted to compare the data with a study done of newly graduated doctors (Faresjö et al., 2007). The questionnaire was completed by nurses one year after graduation. It is therefore retrospective and subject to memory, which may constitute a limitation to the study. The overall response rate $(55 \%)$ was relatively low. However a recent trend in Sweden is lowering participation rates in general for postal questionnaires and around $50 \%$ participation rates is now considered quite reasonable. We have not asked the students for any background facts, just to evaluate their education. Another possible limitation in the study relates to the recruitment of students who may have chosen the IPE University precisely for its IPE. The data were calculated simply by ANOVA when we just wanted to compare the three cohorts. The results strengthen the theory that students who have had an IPE curriculum during their education have a more positive attitude to working with other professions. 


\section{CONCLUDING COMMENTS}

In Swedish health care today and tomorrow it is important to be both "professional and interprofessional competent as a nurse", "to collaborate" and "to communicate" with both staff and patients when health care is moving from a more traditional hierarchically and topdown system to a more teamwork oriented and patient-centred system. In clinical practice patients mostly need help from more than one profession to solve their health problems (Headrick, Wilcock \& Batalden, 1998). Co-operation between professions must increase in modern health care because the body of knowledge is growing rapidly and no profession has a complete overview of the knowledge and skills in many areas.

A metaphor may illustrate traditional education vs. interprofessional education. When a director of a theatre is setting up a production he does not decide to let the actors rehearse their roles separately and then meet each other for the first time on the day when the production is going to be presented for the first time (Wilhelmsson et al., 2009). Unfortunately, in Sweden, as in many other countries, students who are going to work together in health and social care organizations have in most cases not met each other during their education, even though they are going to act every day in the same arena with the same patients and clients.

In summary, this study tries to contribute to the basic issue of evidence for IPE and, compared to the metaphor above, nurses who have been trained in IPE during their undergraduate education seems to be quite well prepared for the premiere evening. 


\section{References}

Anderson, E. \& Lennox, A. (2009). The Leicester Model of Interprofessional Education:

Developing, delivering and learning from student voices for 10 years. Journal of Interprofessional Care, 23 (6): 557-573.

Areskog, N.H. (1992). The new medical education at the Faculty of Health Sciences,

Linköping University - a challenge for both students and teachers. Scandinavian Journal of Social Medicine, 20(1): 1-4.

Areskog, N.H. (2009). Undergraduate interprofessional education at Linköping Faculty of Health Sciences - How it all started. Journal of Interprofessional Care, 23(5): 448-454.

Clark, P. G. (2009). Reflecting on reflection in interprofessional education. Implications for theory and practice. Journal of Interprofessional Care, 23(3), 213-223.

Hansson, A., Foldevi, M., Mattsson, B. (2010). Medical students' attitudes toward collaboration between doctors and nurses - a comparison between two Swedish universities. Journal of Interprofessional Care, 24 (3): 242-250. 
Headrick, L., Wilcock, P., Batalden, P. (1998). Interprofessional working and continuing medical education. BMJ, volume, March 7, 316:771-774.

Fallsberg, M. B. \& Wijma, K. (1999). Student's attitudes towards the goals of an interprofessional training ward. Medical Teacher, 21(6): 576-581.

Fallsberg, M. B. \& Hammar, M. (2000). Strategies and focus at an integrated, interprofessional training ward. Journal of Interprofessional Care, 4: 339-350.

Faresjö, T., Wilhelmsson, M., Pelling, S., Dahlgren, L.O., Hammar, M. (2007). Does interprofessional education jeopardize medical skills? Journal of Interprofessional Care, 21(5): 1-4.

Grant C, Brainbridge L, Gilbert J. (2010). The University of British Columbia model of interprofessional education. Journal of Interprofessional Care, 24 (1): 9-18.

Hind M., Norman I., Cooper, S., Gill E., Hilton, R., Judd, P., Jones, S.C. (2003). Interprofessional perceptions of health care students. Journal of Interprofessional Care, 17:(1): 21-34. 
Hård af Segerstad, H. (1998). The outcome of generic and transferable skills in relation to professional practice. Published in Rust, C (Ed) Improving Student Learning Outcomes, Proceedings of the $19986^{\text {th }}$ International symposium, Oxford Brookes University.

Interprofessional Education Collaborative Expert Panel. (2011). Core competences for interprofessional collaborative practice: Report of an expert panel. Washington, D.C.: Interprofessional Education Collaborativ.

Lee A, Dunston R, Nisbe G, Matthews L, Pockett R. (2009). Interprofessional developments in Australia - L-TIPP (Aus) and the Way Forward. Journal of Interprofessional Care, 23 (3): 315-317.

Pollard, K.C.\& Miers M. (2008). From students to professionals: Results of a longitudinal study of attitudes to pre-qualifying collaborative learning and working in health and social care in the United Kingdom. Journal of Interprofessional Care, 22 (4): 399-416.

Parsell, G., \& Bligh, J. (1998). Educational principles underpinning successful shared learning. Medical Teacher, 20, $522-529$.

Pollard, K.C. (2008). Non-formal learning and interprofessional collaboration in health and social care: the influence of the quality of staff interaction on student learning about collaborative behaviour in practice placements. Learning in Health and Social Care. 2008, 7 (1): 12-26. 
Mandy, A., Milton, C., Mandy, P. (2004). Professional stereotyping and interprofessional education. Learning in Health and Social care, 3: 154-170.

Maslin-Prothero, S. E. \& Bennion, A. (2010). Integrated team working: a literature review. International Journal of Integrated Care, Apr 29; 10: e043.

Molyneux, J. (2001). Interprofessional teamworking: what makes teams work well? Journal of Interprofessional Care, 15(1): 29-35.

Morison, S., Johnston, J. \& Stevenson, M. (2010). Preparimg students for interprofessional practice: Exploring the intra-personal dimension. Journal of Interprofessional Care, 24(4): 412-421.

Ohlsson, U. (2009). The way into a profession - a study of learning and knowledge development among newly graduated nurses. Örebro Studies in Education 26, Örebro Studies in Conditions of Democracy 2, Sweden. 
Rice, K., Zwarenstein, M., Gotlib Conn, L., Kenaszchuk, C., Russel A., Reeves S. (2010). An intervention to improve interprofessional collaboration and communications: A comparative qualitative study. Journal of Interprofessional Care, 24(4): 350-361.

Silén, C. (1996). Assisting Learning - the Tutor Role in Problem Based

Learning. Thesis nr 3: Faculty of Philosophy, Linköping University.

Silén, C. \& Uhlin, L. (2008). Self-directed learning - an issue for students and the faculty! Teaching in Higher Education, 13(4): 461-475.

Swedish Medical Association. http://www.sls.se/

Wackerhausen, S. (2009). Collaboration, professional identity and reflection across boundaries. Journal of Interprofessional Care, 23, 1-19.

Wahlström, O., Sanden, I., Hammar, M. (1996). The student ward at the University Hospital, Faculty of Health and Sciences, Linköping. European Nurse, 1: 262-267. 
Wahlström, O. \& Sandén, I. (1998). Multiprofessional training ward at Linköping University, early experience. Education for Health, 11: 225-231.

Wilhelmsson, M., Pelling, S., Ludvigsson, J., Hammar, M., Dahlgren, L.O., Faresjö, T. (2009). Twenty years experiences of interprofessional education in Linköping - groundbreaking and sustainable. Journal of Interprofessional Care, 23(2): 121-133.

Wilhelmsson, M., Ponzer, S., Dahlgren, L.O., Timpka, T. and Faresjö, T. (2011) Are female students in general and nursing students more ready for teamwork and interprofessional collaboration in healthcare? BMC Medical Education, 11:15.

Wilhelmsson, M., Pelling, P., Uhlin, L., Dahlgren, L. O. Faresjö, T. and Forslund, K. How to think about interprofessional competence: A metacognitive model Journal of Interprofessional Care, 2012, 26(2), 85-91.

World Health Organisation (1978). Declaration of Alma-Ata. International Conference on Primary Health Care, WHO; Alma-Ata, USSR.

World Health Organization (1988). Learning together to work together for health: Technical Report series 769, WHO, Geneva. 
World Health Report (2006). Working Together for Health. The $59^{\text {th }}$ World Health Assembly (WHA.59.23) WHO, Geneva.

World Health Organization (2010). Framework for action on Interprofessional Education and Collaborative Practice. WHO, Geneva. 